\title{
Treatment of pulmonary arterial hypertension
}

\author{
Cláudia Pires Ricachinevsky, ${ }^{1}$ Sérgio Luís Amantéa²
}

\begin{abstract}
Objective: To perform a review of the diagnostic and therapeutic management of pulmonary hypertension in the pediatric population, with emphasis on pharmacological factors.

Sources: Electronic search of publications on the MEDLINE/PubMed, LILACS and Cochrane Collaboration databases. The search strategy adopted gave priority to the identification of clinical trials (controlled or uncontrolled), systematic reviews and directives published during the last 10 years.

Summary of the findings: Many advances have been incorporated into our understanding of pulmonary hypertension during recent years. Issues related to differences in the pathophysiological mechanism of the disease between different age groups have altered both the treatment and prognosis of patients. The combined effect of more selective vasodilatory properties and antiproliferative action and the employment of new drugs are the basic principles of new treatment proposals. In order to be able to gauge the benefits associated with the use of these new therapies, it is of fundamental importance that all patients have their disease correctly diagnosed, the degree of functional compromise classified and their vascular reactivity capacity established, which is more difficult with pediatric patients.

Conclusions: To date there is no treatment that can be considered ideal for the management of pulmonary hypertension. With reference to the possibility of employing new drugs, the majority of studies that have been published were undertaken with adult populations. Few data are available on children, and the majority of studies are uncontrolled trials or case series. Taking into account differences that have already been established between different age groups in terms of disease mechanisms and prognostic aspects, it is difficult to claim that these drugs can be incorporated into the treatment of childhood pulmonary hypertension with the same indications and results.
\end{abstract}

J Pediatr (Rio J). 2006;82(5 Suppl):S153-65: Pulmonary arterial hypertension, pulmonary hypertension, nitric oxide, bosentan, sildenafil.

\section{Introduction}

Pulmonary arterial hypertension (PAH) or pulmonary hypertension $(\mathrm{PH})$ is a rare disease that predominately affects young women, although it can be diagnosed in either sex at any age. ${ }^{1}$ true incidence of PAH is unknown, but it is calculated that one to two new cases of primary $\mathrm{PH}$ per million inhabitants in the general population. 2,3

Secondary $\mathrm{PH}$ is relatively more common, but frequently underdiagnosed. Many patients present a

1. Chefe, UTI Pediátrica, Hospital da Criança Santo Antônio, Complexo Hospitalar Santa Casa, Porto Alegre, RS, Brasil. Intensivista pediátrica, Hospital de Clínicas de Porto Alegre (HCPA), RS, Brasil.

2. Professor adjunto, Departamento de Pediatria, Fundação Faculdade Federal de Ciências Médicas de Porto Alegre (FFFCMPA), Porto Alegre, RS, Brasil. Chefe, Serviço de Emergência Pediátrica, Hospital da Criança Santo Antônio, Complexo Hospitalar Santa Casa, Porto Alegre, RS, Brasil.

Suggested citation: Ricachinevsky CP, Amantéa SL. Treatment of pulmonary arterial hypertension. J Pediatr (Rio J). 2006;82(5 Suppl): S153-65. prolonged interval between onset of symptoms and diagnosis of $\mathrm{PH}$, which delays their treatment and shortens their prognosis yet further. ${ }^{2,4}$

Mortality associated with $\mathrm{PH}$ is extremely elevated. Once diagnosis has been confirmed mean survival among adults is 2.8 years and less than 1 year among children. 3,5

Over the last few years, advances have been associated with earlier diagnosis and a greater understanding of the pathophysiological mechanisms involved. We have come to understand better the association between the degree of vascular compromise and the clinical manifestations presented. These findings have changed both survival and quality of life of these patients.

Nevertheless, in the pediatric population the disease behaves differently. Increased reactivity of pulmonary vessels hinders us from achieving the prognosis established for adult patients. In contrast, this increased reactivity may result in better prognosis in the future, in 
the event that these patients come to benefit from the clinical use of new drugs (with vasodilatory and antiproliferative effects).

\section{Definition and classification}

Pulmonary hypertension is defined as an increase in the mean pressure of the pulmonary artery (PmAP) $\geq 25 \mathrm{mmHg}$ (resting) or $\geq 30 \mathrm{mmHg}$ (exercising). 3,6 when we use the systolic pulmonary artery pressure, we defined hypertension as values above $35 \mathrm{mmHg}{ }^{2}$ Another definition, more adaptable to pediatric practice, takes into account the relationship between pulmonary artery pressure (PAP) and systemic systolic pressure (BP). Accordingly the diagnostic criterion for $\mathrm{PH}$ is: $\mathrm{PAP}>50 \%$ of BP. ${ }^{7}$

Alterations while exercising are particularly important in pediatrics because in children the response of the pulmonary vascular bed to exercise and hypoventilation is exaggerated. ${ }^{3,5}$ Furthermore, it is known that more than $50 \%$ of the vascular bed must be affected (unresponsive or dysfunctional) before symptomology emerges. Nevertheless, during exercise, particularly in children, this lack of response may be present even in very initial phases of the disease. 8

The most recent update to the classification of $\mathrm{PH}$ drawn up during the World Health Organization World Symposium on Pulmonary Hypertension (WHO). This classification was based on advances in the form of histopathological findings, mechanisms involved in molecular and vascular biology in addition to genetic alterations (Table 1). ${ }^{9}$

Primary pulmonary hypertension (PPH), also known as idiopathic, has no definite etiology, is sporadic and has been linked with family-based predisposition (10\% of cases). At the WHO symposium, the term "primary pulmonary hypertension" was officially modified to "pulmonary arterial hypertension idiopathic," reflecting the character of diagnosis by exclusion. Secondary $\mathrm{PH}$ is generally associated with chronic hypoxemia, parenchymatous lung disease, chronic thromboembolic disease, left chamber heart valve disease, myocardial disease, congenital heart disease or connective tissue disease. ${ }^{8}$

\section{Pathophysiology}

Irrespective of the etiology associated with the presence of $\mathrm{PH}$, some of the alterations observed are in common. Similarly, within a single disease associated with the presence of $\mathrm{PH}$, we can observe the damage found exhibits a heterogeneous nature.

In the newborn infant, biological alterations triggered by $\mathrm{PH}$ appear to be: problems with opening the vascular bed and reduction in the number of arteries backspace. In infants, hyperplasia of the tunica intima, with occlusion of pulmonary arterioles and plexiform abnormalities. Adults with $\mathrm{PPH}$ exhibits severe plexiform damage, with abnormalities that are apparently fixed in the pulmonary vascular bed. In contrast, children with PPH suffer more hypertrophy of the pulmonary vessel tunica media and less fibrosis of the tunica intima; as a consequence they suffer less plexiform abnormalities. 3,5

Small infants appear to exhibit a more reactive pulmonary bed, both during vasoconstriction and vasodilation, with $\mathrm{PH}$ crises being triggered more recently than in adults and older children. Histopathological findings suggest that the basic mechanism to be blamed for $\mathrm{PH}$ is the presence of vasoconstriction in these patients. Certain structural and functional abnormalities confirm this theory, but do not explain up to what point some alterations may be cause or consequence. 3,8

The earliest pathological alterations affect the function of vascular endothelium, an important source of local mediators which contribute to the control of vasomotor tonus and structural remodeling. ${ }^{3}$

Functional alterations on the vascular level include reduced production of vasodilatory and antiproliferative substances- prostacyclins, nitric oxide (NO) - and increased production of vasoconstrictive substances and mitogens (endothelin-1).10,11 It appears that a "imbalance" takes place between vasoconstrictor and vasodilator mediators (increased thromboxane and reduced prostacyclins, increased endothelin and reduced NO). Other factors which may also be involved are: serotonin, growth factorderived platelets, angiotensin and loss of vascular NO and prostacyclin due to synthesis genetic expression. ${ }^{3}$ the initial endothelial damage results in recruitment of local vasoactive mediators, provoking a procoagulatory state, leading to consequent vascular obstruction. Furthermore, defects in pulmonary circulation smooth muscle potassium channels also appear to be involved in onset and/or progression of $\mathrm{PH}$

The severity of pulmonary vascular disease can be classified from I to VI:

- Grade I: media hypertrophy;

- Grade II: cellular intimal thickening;

- Grade III: occlusive intimal thickening;

- Grade IV: injuries with vascular dilatation;

- Grade V: plexiform injuries;

- Grade VI: acute necrotizing arteritis.

Grade I to III abnormalities are considered plexogenic (reversible). Grades IV to VI are plexiform (irreversible). Plexiform abnormalities encompass: hypertrophy of the tunica media of preacinar arteries, muscularization of intra-acinar arteries, concentric thickening of the 
Table 1 - Classification of pulmonary hypertension (children and adults) - Venice, 2003

\begin{tabular}{|c|c|c|}
\hline Classification & Type & Etiology \\
\hline Pulmonary arterial hypertension & $\begin{array}{l}\text { Idiopathic } \\
\text { Familial } \\
\text { Associated with connective tissue disease } \\
\text { Associated with congenital heart disease } \\
\text { Associated with portal hypertension } \\
\text { Associated with human immunodeficiency virus } \\
\text { Associated with drugs }\end{array}$ & \\
\hline $\begin{array}{l}\text { Pulmonary hypertension } \\
\text { with left heart diseases }\end{array}$ & $\begin{array}{l}\text { Atrial or ventricular heart disease } \\
\text { Valvular heart disease }\end{array}$ & \\
\hline $\begin{array}{l}\text { Pulmonary hypertension associated } \\
\text { with respiratory diseases with or without hypoxia }\end{array}$ & $\begin{array}{l}\text { Chronic obstructive lung disease } \\
\text { Lung disease interstitial } \\
\text { Sleep apnea } \\
\text { Central alveolar hypoventilation } \\
\text { High altitude } \\
\text { Developmental disorders }\end{array}$ & \\
\hline $\begin{array}{l}\text { Pulmonary hypertension associated } \\
\text { with thromboembolic disease }\end{array}$ & $\begin{array}{l}\text { Obstruction of proximal pulmonary arteries } \\
\text { Obstruction of distal pulmonary arteries } \\
\text { Pulmonary embolism with other etiology }\end{array}$ & $\begin{array}{l}\text { Tumor } \\
\text { Parasitosis } \\
\text { Foreign body }\end{array}$ \\
\hline Miscellaneous & $\begin{array}{l}\text { Sarcoidosis } \\
\text { X histiocytosis } \\
\text { Lymphangiomatosis } \\
\text { External compression (adenopathy, tumor, } \\
\text { Fibrosing mediastinitis) }\end{array}$ & \\
\hline
\end{tabular}

* Source: Third World Symposium on Primary pulmonary hypertension - Venice, 2003.

preacinar arteries, complex alterations and dilatations with arteritis and ferrugination ${ }^{8}$

\section{Clinical progression}

Irrespective of etiology patients with $\mathrm{PH}$ do not exhibit a specific clinical status. Smaller children predominately exhibit symptoms of low cardiac output (failure to thrive, lethargy, irritability, tachypnea and tachycardia). Older children describe a certain degree of respiratory distress, fatigue and headaches (especially from light) and may suffer chest pain (from right ventricular ischemia), episodes of syncope triggered by exertion and, in certain cases, sudden death. Invasive anesthetic and sedative procedures are not welltolerated, and patients with Eisenmenger syndrome may exhibit episodes of hemoptysis. ${ }^{3,5,8}$

Eisenmenger syndrome is defined as vascular pulmonary disease related to congenital heart disease. In these patients vascular disease develops after a hyperkinetic period, with normal vascular resistance and increased pulmonary blood flow. ${ }^{3}$
Clinically, patients progress with pale extremities (due to low cardiac output) and cyanosis (due to low oxygenation) because of intrapulmonary or intracardiac ( $L-R)$ shunts via the foramen ovale.

Some infants may suffer convulsions as a result of exaggerated pulmonary vasoconstriction, but this is a rare complication. In these patients, systemic arterial oxygenation may be reduced during sleep (especially during the first few hours of the morning). ${ }^{3}$

The interval between onset of symptoms and diagnosis is significantly shorter in children. It is rare for the signs of direct heart failure to emerge in children less than 10 years old. In these cases peripheral edema, and acrocyanosis are the signs of terminal disease. ${ }^{3}$

In pediatric patients, cardiovascular auscultation is not as rich, but the pulmonary component is always more audible. Signs of tricuspid regurgitation may be present, and even thoracic deformity may be observed, secondary to severe right ventricular hypertrophy. 3,8

Patients with $\mathrm{PH}$ can be classified according to their functional capacity (degree of functional limitation) (Table 2). 
Table 2 - Functional classification (World Health Organization)*

\begin{tabular}{|c|c|c|}
\hline Classes & Prescribed physical activity & Symptomology \\
\hline I & $\begin{array}{l}\text { Patients with } \mathrm{PH} \text { and no limitation } \\
\text { of physical activity }\end{array}$ & $\begin{array}{l}\text { Physical activity does not cause dyspnea, } \\
\text { chest pain, tiredness or syncope }\end{array}$ \\
\hline II & $\begin{array}{l}\text { Patient with } \mathrm{PH} \text { and mild limitation } \\
\text { of physical activity }\end{array}$ & $\begin{array}{l}\text { Patient comfortable at rest. } \\
\text { Everyday physical activity causes dyspnea, } \\
\text { chest pain, tiredness or "near" syncope }\end{array}$ \\
\hline III & $\begin{array}{l}\text { Patient with PH with and marked limitation } \\
\text { of physical activity }\end{array}$ & $\begin{array}{l}\text { Patient comfortable at rest. } \\
\text { All and any physical activity causes dyspnea, } \\
\text { chest pain, tiredness or "near" syncope }\end{array}$ \\
\hline IV & $\begin{array}{l}\text { Patient with PH incapable of any } \\
\text { physical activity whatsoever without } \\
\text { causing symptomology }\end{array}$ & $\begin{array}{l}\text { Patients with signs of DHF. Dyspnea and/or fatigue } \\
\text { may be present at rest. Distress is increased by any } \\
\text { physical activity whatsoever }\end{array}$ \\
\hline
\end{tabular}

$\mathrm{PH}=$ pulmonary hypertension; $\mathrm{DHF}=$ diastolic heart failure.

${ }^{*}$ New York Heart Association/WHO functional classification.

\section{Diagnostic assessment methods}

Diagnosis of $\mathrm{PH}$ is by exclusion, but there maybe a high degree of clinical suspicion. Family history should be thoroughly investigated for: connective tissue disorders, relatives with $\mathrm{pH}$, congenital heart disease, other congenital malformations and any history of sudden death in the family. Drug use should also be investigated (especially psychotropics and appetite suppressants) as should exposure to altitude, repeated respiratory infections, obstructive sleep apnea (not so rare in children), thromboembolic events (rare in pediatrics) and neonatal antecedents. $3,12,13$

As can be observed in Table 3, the routine for diagnostic evaluation may include a series of supplementary tests adapted to the individual clinical requirements of each patient.

Echocardiographic examination is an extremely sensitive and non-invasive diagnostic method which has made it first imaging examination to be used with patients with a clinical suspicion of $\mathrm{PH}^{2,4}$ The echocardiogram evaluates right ventricular function, which traces the progressive damage resulting from the disease, and is of fundamental importance for sequential monitoring of $\mathrm{PH}$ patients. ${ }^{14,15}$ By means of this examination we can exclude cardiological causes of $\mathrm{PH}$, such as right ventricular dysfunction, mitral valve disease and the presence of intracardiac shunt. ${ }^{4}$

Transthoracic Doppler echocardiogram is used to estimate systolic pressure in the right ventricle (RV) by means of tricuspid regurgitation velocity measurements. The sum of right atrial pressure with peak tricuspid regurgitation flow velocity gives an accurate figure for peak pulmonary pressure. ${ }^{2}$ This figure offers good correlation with systolic pressure at the pulmonary artery. ${ }^{16}$ However, it is known that RV systolic pressure can be underestimated in patients whose tricuspid regurgitation velocity is reduced. ${ }^{4}$

Cardiac catheterization is considered the gold standard for the diagnosis of $\mathrm{PH}$ and for determining of. 2,4,6 Practically all patients with $\mathrm{PH}$ should undergo right cardiac catheterization for the measurement of PAP (mean, systolic and diastolic), pulmonary capillary wedge pressure, cardiac output and oxygen saturation and to calculate pulmonary vascular resistance (PVR) and shunts. Pulmonary vascular resistance, cardiac output, and central venous saturation are the most important prognostic parameters in $\mathrm{PH}$.

Is examination to evaluate pulmonary vascular response to vasodilators: a fall in PAP to below $40 \mathrm{mmHg}$, a drop of more than $20 \mathrm{mmHg}$, or of more than $20 \%$ of baseline. All are considered as a positive hemodynamic response (response test). $3,6,8$

The severity of PH is classified as mild ( $P_{m}$ AP from 25 to $40 \mathrm{~mm} \mathrm{Hg}$ ), moderate ( $P_{m} A P$ from 41 to $55 \mathrm{mmHg}$ ) or severe $\left(P_{m} A P>55 \mathrm{mmHg}\right) .{ }^{17}$ cases of $\mathrm{PH}$ secondary to heart disease or chronic lung disease are generally related to mild to moderate increases in pulmonary pressure. Patients with severe $\mathrm{PH}$ are generally suffering from $\mathrm{PPH}$, connective tissue disease, or chronic thromboembolism. ${ }^{14}$

Some patients with mild $(25-40 \mathrm{mmHg})$ to moderate PH (41-55 $\mathrm{mmHg})$, secondary to chronic hypoxemia, 
Table 3 Diagnostic assessment routine

\begin{tabular}{ll}
\hline Supplementary examination & Observations \\
\hline $\begin{array}{l}\text { Chest X-ray } \\
\text { Pulmonary function and }\end{array}$ & $\begin{array}{l}\text { Widened pulmonary trunk and proximal bronchial branches, with discrepant thinning } \\
\text { of peripheral branches ("tree branches" appearance), is highly suggestive of PH. } 8\end{array}$ \\
gasometry tests & $\begin{array}{l}\text { May be normal, but must be performed in order to rule out lo pulmonary trunk lung disease. } \\
\text { Gasometry (or just oximetry) analysis at rest and post-exercise can be useful for } \\
\text { tracking disease progression. }\end{array}$
\end{tabular}

Laboratory assessment

Initial tests include complete blood test, prothrombin time, activated partial thromboplastin time, liver function tests, autoimmunity panel and HIV test. ${ }^{2}$

Echocardiogram with color Doppler

Computerized tomography of the chest

Angiotomography (ventilation/perfusion tomography)

Magnetic resonance imaging

Pulmonary angiography

Pulmonary biopsy

Walking test
A sensitive noninvasive diagnostic method, being the first examination to be performed with patients with clinical suspicion of $\mathrm{PH} .{ }^{2,4}$ Transthoracic Doppler echocardiogram is used to estimate RV systolic pressure, which offers a good correlation with PA systolic pressure, confirmed by simultaneous measurements by right cardiac catheterization. ${ }^{16}$

Indicated for differential diagnosis of $\mathrm{PH}$ patients. The high technological standard has brought the technical result of CT scans within reach of those of pulmonary angiography. ${ }^{8}$

The most useful screening test for pulmonary thromboembolism. Should be performed before a diagnosis of PPH is established. One or more perfusion segments or defects is a finding highly suggestive of thromboembolism ("moth-eaten" appearance). In $\mathrm{PPH}$, angiotomography is normal. 2,4

Provides information on the size and function of the RV, myocardial thickness, presence of chronic thromboembolism and pulmonary and cardiac pressures.

Indicated for patients with chronic thromboembolic pulmonary hypertension, primarily in potentially-surgical cases, for which it aids in locating the embolism and defining its extent. ${ }^{4}$

This technique is no longer used with $\mathrm{PH}$ patients, due to elevated risks of the procedure itself. Transbronchial biopsy is not sufficient to choose material to be sampled and involves an elevated risk of bleeding. ${ }^{8}$ Biopsy is reserved for cases where histopathological diagnosis is necessary, such as vasculitis, granulomatous disease, venoocclusive disease or interstitial disease. ${ }^{4}$

A simple test that offers good correlation with patient survival. Should be undertaken at the time of diagnosis (to establish baseline impact on function) and during follow-up, assessing response to treatment and prognosis. It can be performed by patients 5-years and older.

$\mathrm{PA}=$ pulmonary artery; $\mathrm{PH}=$ pulmonary hypertension; $\mathrm{PPH}=$ primary pulmonary hypertension; $\mathrm{RV}=$ right ventricle.

pulmonary pathologies or collagen disorders, can be monitored serially with echocardiograms (every 3 to 6 months) and cardiac catheterization can be reserved for those cases that pass functional class III on the New York Heart Association (NYHA) scale. ${ }^{4}$

Catheterization is particularly indicated to rule out congenital heart disease, occult shunts and stenosis of the distal pulmonary artery.

The risk-benefit ratio should always be taken into account when indicating cardiac catheterization for pediatric patients with. Figure 1 is a diagnostic assessment flow diagram for patients with $\mathrm{PH}$.

\section{Treatment}

To date, there is no cure, or even a therapeutic approach that can be recommended in a universal manner for all $\mathrm{PH}$ patients. However, recent advances in the physiopathogenesis of $\mathrm{PH}$ and the emergence of new pharmaceuticals, with selective vasodilatory effects on the pulmonary vascular bed, contribute to improving these patients' survival.

Noninvasive investigative procedures are always indicated (before and after any treatment that is instituted) for patients with $\mathrm{PH}$, with the aim of finetuning treatment. ${ }^{3}$ 


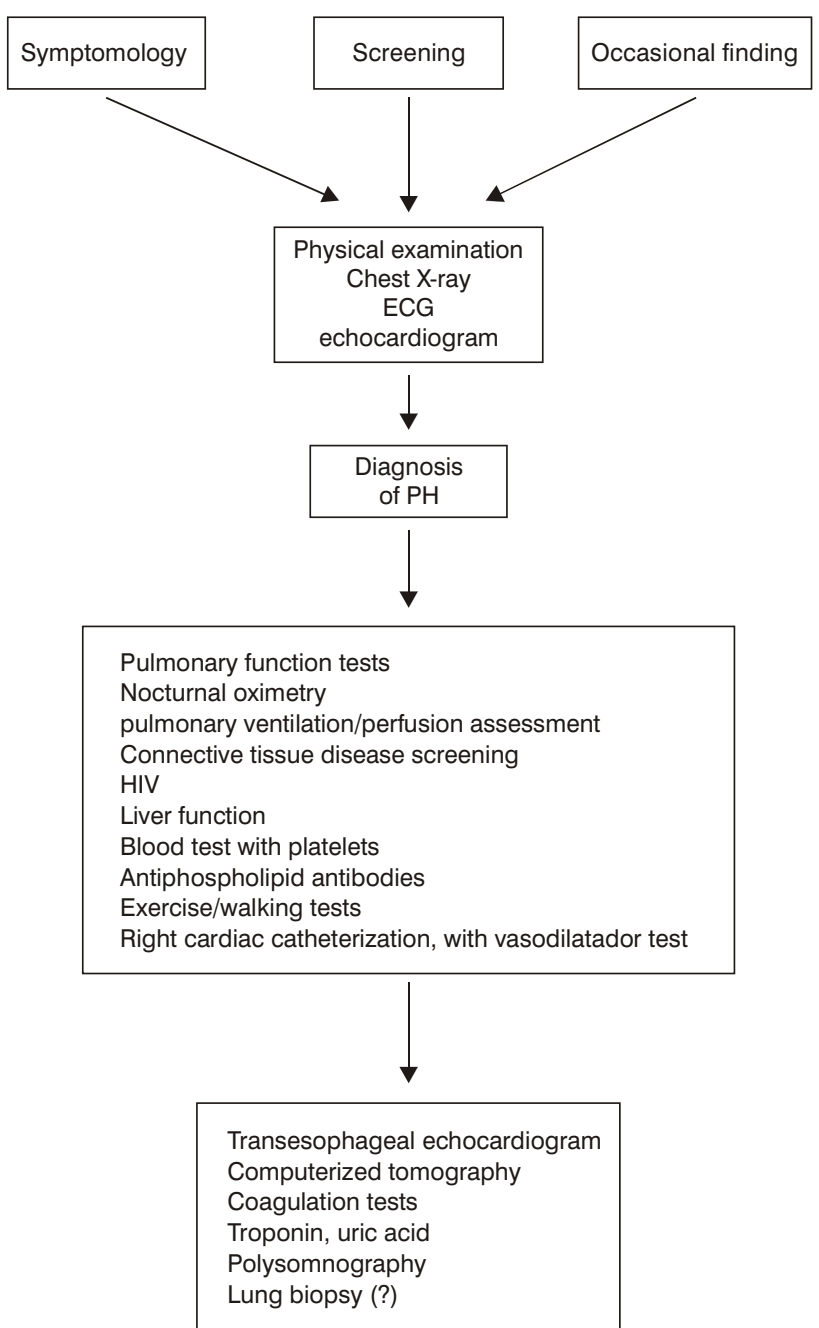

Figure 1 - Flow diagram for diagnostic assessment of pulmonary hypertension

$E C G=$ electrocardiogram; HIV = human immunodeficiency virus; $\mathrm{PH}=$ pulmonary hypertension.

\section{General management}

Pulmonary circulation is reduced in patients with $\mathrm{PH}$. Increased oxygen demand may aggravate $\mathrm{PH}$ and diastolic heart failure (DHF), therefore physical activities are restricted (risk of effort syncope). ${ }^{18}$

Children with $\mathrm{PH}$ have greater pulmonary vascular reactivity than do adults. Respiratory infections should be treated and prevented (immunization for influenza and pneumococcus).

Emphasis should be given to contraception for patients at fertile ages (pregnancy and delivery are contraindicated.) $)^{18}$

The indication of chronic anticoagulation in patients with ph is based on histopathological studies and postmortem findings obtained from adults..3,19,20 Rational anticoagulation usage, with the aim of preventing secondary in situ thrombosis, is only justified those patients with documented right ventricular failure and low pulmonary flow (DHF). No indication for chronic anticoagulation has yet been established for pediatric patients with $\mathrm{PH}$ (considering risks/benefits/safety/efficacy.) In severe cases of DHF, in analogy with adults, anticoagulation is recommended with warfarin or heparin. Neither aspirin nor dipyridamole are indicated because their efficacy has not been confirmed in low-flow zones, where the risk of thrombosis in situ is elevated. ${ }^{3}$

The efficacy of pulmonary vasodilator therapy has been limited by the absence of selectivity and potency. The majority of drugs considered pulmonary vasodilators also have systemic vasodilator action and their effect on pulmonary circulation is not so marked. Therefore the apparent benefits may be secondary to reduced preload and reduced $\mathrm{RV}$ work. ${ }^{11}$

Calcium channel blockers, digitalis and diuretics have limited indications in pediatric patients with ph, since the efficacy of these medications has not been confirmed. Patients with $\mathrm{PH}$ accompanied by signs of DHF, with hepatic and systemic congestion, should obtain some benefit from reduced afterload and a certain inotropic effect, but great care must be taken because of the risk of concomitant preload reduction, which would worsen cardiac output. ${ }^{5}$ In adults, less than $20 \%$ of patients exhibited a response to chronic calcium channel blocker s (nifedipine, amlodipine), when assessed with exercise and hemodynamic testing and according to clinical symptomology. ${ }^{21}$ Among patients who respond to this treatment, less than $7 \%$ maintained the beneficial effect over the long term. ${ }^{22}$ Potential associated side effects are: hypotension, pulmonary edema, RV failure and risk of death. 6

The use of calcium channel blockers, diuretics and digitalis has not been recommended as routine in children with $\mathrm{PH} .{ }^{2,3}$ notwithstanding, during exacerbations and crises, it may be necessary to provide intravenous inotropic support.

Oxygen therapy is recommended for patients with $\mathrm{PH}$ secondary to parenchymatous pulmonary disease. Patients with Eisenmenger syndrome or $\mathrm{PPH}$ do not appear to benefit from this treatment, although nocturnal oxygen therapy may delay progression of polycythemia in those who have Eisenmenger syndrome. ${ }^{5}$ Children who exhibit reduced oxygen saturation during the night (in the absence obstructive disease or apnea) may benefit from the administration of nocturnal oxygen. During these episodes patients may present with severe crises of dyspnea and syncope, with or without convulsive hypoxemic crises. ${ }^{5}$ Continuous oxygen may be indicated for children with severe DHF, with hypoxemia during sleep, and markedly elevated oxygen extraction. 5 
Oxygen therapy is recommended for patients who will travel by air or have symptomatic respiratory infections, because of the risk of triggering $\mathrm{PH}$ crises. ${ }^{6}$

When oxygen therapy is indicated, the objective is to maintain oxygen saturation above $90 \%$ (except in those patients who have cyanotic congenital heart disease). ${ }^{18}$

\section{Prostacyclins}

The use of prostacyclins (epoprostenol) or prostacyclin analogues for $\mathrm{PH}$ treatment is based on a "imbalance" between thromboxane and prostacyclin metabolites. 3,6,23-25

Prostacyclins induce relaxation of the respiratory vascular musculature, stimulating production of cyclic adenosine monophosphate (AMP), and inhibit respiratory muscle cell growth and platelet aggregation. ${ }^{18}$

In 1996, Barst conducted an open, prospective and randomized study with 81 patients with $\mathrm{P} \mathrm{H}$ and NYHA functional class III or IV. Patients were randomized to receive either conservative treatment in isolation (anticoagulants, diuretics, oral vasodilators and oxygen), or conventional therapy in combination with continuous intravenous epoprostenol. After 12 weeks of treatment, the group given epoprostenol showed improvements in the walking test, reduction in PmAP and PVR, with no deaths. The group treated with conventional therapy exhibited deterioration in all of these criteria and eight patients died. 26 based on the results of this study prostacyclins were approved for the treatment of patients with (Europe and North America). Although prostacyclins are vasodilators, it appears that the chronic benefits from their use are associated with an antiproliferative property. Used with patients with advanced disease (absence of pulmonary vascular reactivity) confirmed a "rescue" effect on the pulmonary vascular endothelium restoring normal function. 6

Epoprostenol is administered intravenously and appears to be effective with patients at functional classes II to IV, with a 6 minute walking test $\leq 330 \mathrm{~m} \cdot{ }^{20,27}$ Several different follow-up studies of patients with $\mathrm{PPH}$ have demonstrated significantly improved prognosis (5-year survival of $55-28 \%$ ) in those patients who exhibited improvements in NYHA functional class and the walking test after 3 months of treatment. In those patients who did not demonstrate improvement after 3 months of treatment (1/3 of the patients), prognosis was equal to that of the controls. 28,29

This drug has demonstrated good results in children with severe $\mathrm{PH}$ associated with congenital heart disease; 8 patients with $\mathrm{PH}$ associated with HIV infection and portal hypertension. However, it does not appear to influence the mortality of patients with $\mathrm{PH}$ secondary to collagen disorders. $27,30,31$
Parenteral administration of prostacyclins is complex, because it requires a "fully implantable" intravenous catheter for continuous infusion. Dosage is variable, between $21 \pm 7 \mathrm{ng} / \mathrm{kg} / \mathrm{min}$ during the first year and $32 \pm 10 \mathrm{ng} / \mathrm{kg} / \mathrm{min}$ after 41 months. ${ }^{18}$ Several adverse effects have been reported: maxillary pain, headaches, diarrhea, nausea, leg pains, rubor and complications associated with the infusion system (risk of severe infections and sepsis: 0.1 to 0.6 case/patient/year). ${ }^{18}$

Despite offering proven functional improvement for patients, epoprostenol is far from being considered an ideal treatment. In addition to its inaccessible price, administration is complicated and it is associated with several adverse effects.

Teprostinil is a prostacyclin analogue that can be given in continuous subcutaneous (or intravenous) infusion. It was developed to avoid the complications resulting from intravenous catheters. In a randomized and controlled study involving 470 patients with $\mathrm{PH}$ of varying etiology, there were improvements in walking test results and in clinical symptomology (although not so evident as with intravenous prostacyclin). ${ }^{32}$ Teprostinil has been approved in the USA for use with adults with $\mathrm{PH}$ since 2002, but, because of effects associated with pain resulting from infusion, it is contraindicated for pediatric use. 3,8

Iloprost is an inhaled prostacyclin analogue. Its particle size $(0.5$ to $3.0 \mu \mathrm{m})$ guarantees it pulmonary selectivity and improved tolerance. 6,8 However, its short half-life (45 minutes) demands frequent administrations ( 6 to 12 times per day) ${ }^{8} \mathrm{~A}$ randomized, multicenter study carried out in Europe and involving 207 patients with $\mathrm{PH}$ of varying etiology, assessed response after 12 weeks of treatment with iloprost, in terms of walking test improvements and NYHA functional class. Against these criteria, treated patients exhibited improvements in relation to placebo. The adverse symptoms presented are: coughing and those effect resulting from the drug's vasodilator effect.

There are no studies that have evaluated its effects over the long term, and clinical experience with children is still extremely limited. ${ }^{3}$ Inhaled iloprost is licensed for use in Europe and the USA. The dose varies depending upon the response of each patient. It is administered via a special nebulizer, and the maximum daily dose is $45 \mathrm{mcg}$. A small proportion of patients appear to respond in isolation. 33

The oral prostacyclin analogue (beraprost) has around $50 \%$ of the effect of epoprostenol, with a longer half-life. Its hemodynamic effects over the long term (over 6 months) have not yet been fully confirmed. 34,35 This drug is not yet approved for pediatric use. ${ }^{25}$

\section{Endothelin receptor inhibitors}

In patients with $\mathrm{PH}$, endothelin-1(A) levels are elevated in plasma, and are inversely correlated with prognosis. ${ }^{18}$ 
It is known that endothelin-1 is a powerful vasoconstrictor, being involved in the pathogenesis of $\mathrm{PH} .{ }^{36}$ Bosentan is an oral endothelin receptor antagonist. This drug has a discretely greater affinity for $\mathrm{ET}_{\mathrm{a}}$, and its pharmacological action is by means of vasoconstriction inhibition and the action of mitogenesis and remodeling (activated by endothelin-1 in pulmonary arteries). 37

Channick et al. ${ }^{38}$ performed a placebo-controlled clinical trial of bosentan with 33 adult patients, demonstrating improvements in $\mathrm{PH}$ functional class (NYHA/WHO) and walking test results. ${ }^{38}$ Later, Rubin et al., in a similar experiment, with a larger number of patients $(n=213$ ) ( $n=213$ ), demonstrated improvement in functional class is and walking test and increase in disease progressionfree survival (period with no need for transplantation, atrial septostomy, continuous hospital care or death). ${ }^{10}$ Galiè et al., assessed adult patients treated with bosentan by echocardiogram, finding increased cardiac index, RV systolic function, and initial diastolic filling of the left ventricle (LV), leading to a reduction in RV dilatation LV size. 39

Bosentan should not be used during pregnancy because of the potential for teratogenesis (animal experiments). Serial liver function tests should be carried out, because of the risk of hepatotoxicity in $6 \%$ of patients (dosedependent effect). ${ }^{8}$

Approval for use with adult $\mathrm{PH}$ patients was granted in 2001 in the USA, and in 2002 in Europe. ${ }^{18}$ More recently, the drug was licensed for use in Brazil (2005).

Data on bosentan in the pediatric population are limited. Barst et al. performed an open, uncontrolled study involving 19 patients originally treated at two centers (New York and Colorado). These patients had functional class II or III and weighed more than $10 \mathrm{~kg}$. A $13 \%$ reduction in PmAP was observed. However, no changes were observed in walking test results or functional class. Apparently, the pharmacokinetic and hemodynamic effects of bosentan were similar to those observed ion adult patients. The Food and Drug Administration (FDA) approved the drug for use with children over 12 years or with weight $>40 \mathrm{~kg}$ on the basis of this study. ${ }^{36}$

Rosenzweig et al. performed a retrospective study involving 86 children with $\mathrm{PH}$ of varying etiology. They were given long-term bosentan (14 months), in isolation or concurrently with prostacyclins. The children were evaluated in terms of hemodynamic variables and functional class (WHO classification). There were reductions in PmAP $(64 \pm 3 \mathrm{mmHg}$ to $57 \pm 3 \mathrm{mmHg})$ and PVR $\left(20 \pm 2 \mathrm{U} \mathrm{xm}^{2}\right.$ to $15 \pm 2 \mathrm{U} \mathrm{xm}^{2}$ ), and improvements in functional class in $46 \%$ of the patients. 40

The suggested dose is $62.5 \mathrm{mg}$ (twice a day for the first month), followed by progressive increases until the ideal dose of $125 \mathrm{mg}$ is reached (twice a day), making a total daily dose of $250 \mathrm{mg} .{ }^{36}$
Other selective $\mathrm{ET}_{\mathrm{a}}$ inhibitors, such as sitaxsentan and ambrisentan, are under investigation for use in $\mathrm{PH}$. These drugs' action is based on a blockade of the vasoconstrictor effect of $\mathrm{ET}_{\mathrm{a}}$ receptors, while maintaining vasodilation and clearance of $\mathrm{ET}_{\mathrm{b}}$ receptors. The risk of hepatotoxicity is similar to with bosentan, and so far no license has been granted in the USA. ${ }^{41,42}$

\section{Nitric oxide}

Nitric oxide is an inhaled vasodilator with a selective action on pulmonary circulation. It activates the guanylylcyclase enzyme in pulmonary smooth muscle vascularization, which increases cyclic guanine monophosphate (GMPc) and reduces intracellular calcium concentration, resulting in vasodilation. ${ }^{3}$ Administered by inhalation, NO rapidly binds to hemoglobin in pulmonary capillaries, inactivating it. This makes it a selective pulmonary vasodilator, capable of attenuating the pulmonary vasoconstriction induced by hypoxia or other vasoconstriction agonists, without producing significant systemic vasodilation. It is not yet known whether NO has antiproliferative properties in the pulmonary vascular bed. 6,43

The use of $\mathrm{NO}$ for persistent $\mathrm{PH}$ in the neonate 44 and for the management of congenital heart disease (especially during the immediate postoperative period) ${ }^{45}$ are wellestablished. Prophylactic use for patients with risk of $\mathrm{PH}$ during post-op for correction of congenital heart disease is controversial. 46 Similarly, chronic NO use for $\mathrm{PH}$ treatment also requires further investigation. There are reports of tachyphylaxia, in addition to difficulties related with administration logistics and elevated cost. 47

The same benefits have been reported from NO (antiproliferative and/or platelet antiaggregants) as are offered by chronic epoprostenol use; ${ }^{6}$ although so far without adequate foundation. ${ }^{3}$

Nitric oxide has been used to assess pulmonary vascular reactivity and its in a hemodynamic study by cardiac catheterization. ${ }^{6}$

Unfortunately, the elevated cost of NO (approximately US $\$ 100.00 / \mathrm{h}$ ) has restricted its use at some centers. Currently, many Latin American countries no longer make NO routinely available and, even in European countries, attempts have been made to employ the gas more selectively. ${ }^{46}$

The European consensus recommendation is to start at $20 \mathrm{ppm}$ and observe the response for $10 \mathrm{~min}$. Sequentially increase to $40 \mathrm{ppm}$ and observe the response over a short period of time, around $30 \mathrm{~min}$ (no more than 2 hours). The response criteria are a reduction in PAP and/or at least a $20 \%$ improvement in oxygenation saturation over baseline. Patients who do not respond to $40 \mathrm{ppm}$ will probably not respond to $80 \mathrm{ppm}$ either. As soon as a response is 
observed and the patient stabilized, it is recommended that NO be reduced to 10 to 5 ppm. ${ }^{46}$

\section{Phosphodiesterase inhibitors}

Nitric oxide is a powerful, short-acting pulmonary vasodilator. Within the smooth muscle it activates the guanylyl-cyclase enzyme, which generates GMPc, which in turn relaxes smooth muscle. Phosphodiesterase (PDE) is responsible for degrading GMPC.

Sildenafil is a potent and selective PDE type 5 inhibitor, better known for its clinical indication to correct male erectile dysfunction. In addition to its wide distribution across the corpora cavernosa, it also reaches high concentrations within the pulmonary vascular smooth muscle, the trachea and in platelets. ${ }^{11}$ Phosphodiesterase inhibitors ${ }^{5}$ appear to accrue added benefits when used together with NO. In this situation, abrupt withdrawal of the gas can precipitate a sudden elevation in PAP. ${ }^{48,49}$

The first cases of the clinical application of sildenafil to $\mathrm{PH}$ treatment were conducted by Atz et al., who reported on three patients with diagnoses of total anomalous pulmonary venous drainage (TAPVD) presenting with $\mathrm{PH}$ during the immediate postoperative period. These patients were effectively controlled with ON, but presented problems for gas withdrawal. For all three patients (two infants and a neonate), GMPc assays were performed and, after oral sildenafil was given, levels rose significantly, allowing the gas to be withdrawn definitively. 48

Later, reports of the treatment of two adult patients and one child suffering from $\mathrm{PH}^{49,50}$ provided evidence of improved capacity to perform exercise and improved quality of life, with no evidence of adverse effects associated with the drug. 51

Starting from the case reports, studies emerged employing animal PH models (induced with monocrotaline, thromboxane, or by hypoxia). These studies proved capable of demonstrating improvements in hemodynamic variables, with concomitant elevation of plasma GMPc levels. These studies also attempted to define the appropriate dose by patient weight for adults (using three comparative doses), which proved useful for estimation of the pediatric dose. $49,52-55$

A study carried out by Kleinsasser et al., with normal pigs (free of $\mathrm{PH}$ ), assessed hemodynamic and gaseous exchange parameters with three progressive doses of sildenafil. The authors demonstrated that the reduction in PVR is dose-dependent and makes ventilation/perfusion more heterogeneous (with increased R-L intrapulmonary shunt) and can lead to reduced arterial oxygen saturation. This effect was not observed with low doses, but at intermediate and high dosages. 56

A consensus of specialists agreed on the use of sildenafil with patients suffering from cardiovascular disease in 1999. They reported it as safe as a result of its $\mathrm{PDE}_{5}$ selectivity (in preference to $\mathrm{PDE}_{3}$ ), without causing significant inotropic effects. 57

Original studies of the pharmokinetics of sildenafil, carried out with healthy volunteers, demonstrated good enteral absorption (peak plasma levels 30-120 minutes after administration), with a half-life of 4 h. 57 Patients using nitrates concurrently may present hypotension. 47,57 In terms of its presentation for clinical use, it is available in inhaled, oral and intravenous formulations. ${ }^{3}$

There is no information on interactions with other $\mathrm{PDE}^{3}$ inhibitors (milrinone, amrinone, enoximone or vesnarinone). Similarly, there is no information on its use in association with platelet antiaggregants (dipyridamole, clopidogrel or ticlopidine). No pharmacokinetic interactions were observed when sildenafil was given in association with acetylsalicylic acid. 57

The medical literature contains few controlled clinical trials assessing the efficacy and safety of sildenafil (oral, inhaled or intravenous) for $\mathrm{PH}$, in comparison with other pulmonary vasodilators (NO, prostacyclins and bosentan). Some studies carried out with experimental models of $\mathrm{PH}$ have been published. 53,54

With relation to the pediatric population, there are only case reports that demonstrate possible clinical benefits from the use of sildenafil for $\mathrm{PH} .{ }^{48,58} \mathrm{~A}$ recent systematic literature review by Cochrane, drawing on material from several databases (MEDLINE, EMBASE and CINAHL), selected just four controlled clinical trials, involving 77 patients (adults and children). Two of these studies assessed the acute effects of sildenafil, while the other two assessed effects over the long term. ${ }^{11}$ Many questions therefore remain about the true efficacy of sildenafil for the treatment (chronic and acute) of patients with $\mathrm{PH}$, and it is still necessary to define dosage, intervals and safety for pediatric patients.

Wilkens et al. studied five patients with $\mathrm{PPH}$, comparing the prescription of inhaled prostacyclin in isolation (iloprost) with oral sildenafil and with both drugs in combination. They observed acute reductions in PmAP in all groups, with the least response being to sildenafil alone and the greatest to the combined treatment. 59

Leuchte et al. assessed a group of 10 patients with $\mathrm{PPH}$, comparing NO, iloprost and oral sildenafil. Both drugs caused an acute reduction in PAP, a reduction in PVR and an increase in cardiac output; iloprost provoked the best response (20\% reduction in PAP). ${ }^{1}$

López-Guarch et al. assessed long term effects of sildenafil on 11 patients with $\mathrm{PPH}$, with clinical deterioration despite chronic prostacyclin use. These patients exhibited improved walking tests, $\mathrm{PH}$ functional class and echocardiographic measurements (reduced RV diameter and LV diastolic index). ${ }^{60}$ 
Chockalingam et al., in an uncontrolled clinical trial, assessed the effects of sildenafil prescribed in isolation, for 4 weeks, on 15 adults with PPH. The majority of these patients $(80 \%)$ exhibited improved functional class, Borg dyspnea index, walking test and PAP (evaluated by echocardiography). Therapeutic failure was observed in $20 \%$ of the patients, even when the drug dose was increased. 15

More recently, two new clinical trials were performed with adult populations. They compared sildenafil with oral prostacyclin (beraprost) and intravenous prostacyclin (epoprostenol). Kataoka et al. assessed the long-term effects on 20 adult patients with PPH refractory to treatment with epoprostenol. They observed improvement in hemodynamic variables (PVR, PAP and RA diameter), tolerance of exercise and functional class. ${ }^{61}$ Ikeda et al. assessed, acutely, six adult patients with $\mathrm{PH}$ of varying etiology by means of hemodynamic studies. They observed reductions in PAP and PVR, with the change being greatest when sildenafil was combined with beraprost. 62

Trache et al., in a retrospective study, reported on eight adult patients with $\mathrm{PH}$ (heart surgery post-op) who were given oral sildenafil as an adjuvant therapy when weaning them from other pulmonary vasodilators (sodium nitroprusside, nitroglycerine and NO). They observed PAP reduce (a fall of $20 \%$ from baseline), allowing sequential weaning from all the other drugs after the first dose of sildenafil. 63

The largest patient sample used to assess the effects of sildenafil on pediatric patients was reported on by Schulze-Neick et al. The sample comprised 24 children with $\mathrm{PH}$ secondary to congenital heart disease. This study, controlled with inhaled NO, assessed 12 children by cardiac catheterization and 12 by hemodynamic monitoring during the immediate postoperative period. Intravenous sildenafil was more effective for reducing PVR than was ON. It caused am increase in GMPc 2 to 2.4 times greater than with $\mathrm{NO}$ in isolation. The selective pulmonary vasodilator effect of sildenafil with associated with increased intrapulmonary shunt, which was not clinically significant in this study, but which could represent an undesirable effect if we consider patients in the postoperative period of congenital heart disease surgery. 64

In Brazil, Bentlin et al. reported on the use of sildenafil with a neonate in the immediate postoperative period of heart surgery. The patient exhibited good tolerance and response, despite not having responded to inhaled NO previously. 65

There arte few adverse effects described in pediatric patients: penile pain and erections were observed in normal patients after accidental consumption of elevated doses of sildenafil ( $5 \mathrm{mg} / \mathrm{kg}$ ) ${ }^{66,67}$ In a neonatal study, Marsh suggested that retinopathy of prematurity may be exacerbated after sildenafil use. This report, however, involved an extremely premature patient, using oxygen at high concentrations and for a prolonged period, which, by themselves, would already explain this occurrence. 68,69

A recent study carried out by our research team, involving 26 pediatric patients with $\mathrm{PH}$ (varying etiology), demonstrated an acute reduction in PmAP of $20 \%$ of baseline. Patients were divided into two groups: one assessed echocardiographically and the other hemodynamically by invasive monitoring during the postoperative period of heart surgery. This reduction was accompanied by a reduction in central venous pressure (CVP), elevation in oxygen saturation and reduction in heart rate, with those patients with postoperative $\mathrm{PH}$ tending to elevated PAM. The group assessed by echocardiogram was placebo-controlled and also exhibited reduced PAP, with no repercussions on other variables. ${ }^{70}$

The true role of this drug for patients with $\mathrm{PH}$ has not yet been established, but it appears to be a useful alternative for weaning from $\mathrm{NO}$ and during acute $\mathrm{PH}$ crises.

\section{Combined treatment}

The combined use of drugs which have different sites of action appears to be promising for $\mathrm{PH}$ treatment. Adjuvant use of bosentan and sildenafil with patients already on prostacyclin (oral, inhaled or intravenous) improved the variables under analysis. ${ }^{71,72}$ Further studies are needed to determine the true combined effects of these drugs, particularly in the pediatric population.

\section{Surgical options (and transplantation)}

Children with frequent syncope and DHF have poor prognosis. Effort-induced syncope occurs because of an inability to increase cardiac output to maintain cerebral blood flow. A patent foramen ovale is capable of increasing these patients' survival. Systemic arterial oxygen saturation declines, but cardiac output and oxygen supply to tissues improve, through the shunt. Despite experience with more than 100 patients with atrial septostomies for $\mathrm{PH}$, the procedure is still considered investigative. ${ }^{73,74}$

Cardiopulmonary or just pulmonary (unilateral or bilateral) transplantation has been indicated for patients with PH since 1981. Currently, combined transplantation is only indicated in cases of anatomical cardiac defects, with no possibility of surgical correction, since morbidity and mortality are higher. Overall surgical mortality for lung transplantation is 16 to $29 \%$. Pediatric data from the International Society for Heart and Lung 
Transplantation demonstrate 2-year survival of $65 \%$ and 5-year survival of $40 \% .75,76$

Transplantation is not the perfect treatment for $\mathrm{PH}$, being linked with greater post-transplantation morbidity and mortality than among those patients whose indication is a different disease. Currently, transplantation is recommended for a specific group of patients, who do not respond to vasodilatador therapy, or who exhibit clinical/hemodynamic deterioration during vasodilator therapy (isolated or combined drug use). 3,77

\section{Conclusions}

The management of $\mathrm{PH}$ is a challenge, even to more experienced clinicians. Recent advances in understanding the pathophysiologic mechanisms involved indicate that there are differences in disease presentation in the pediatric population. New drugs have emerged and opened up fresh prospects for medium and long-term prognosis.

Figure 2 is our suggestion for the therapeutic management of patients with $\mathrm{PH}$ in the form of a flowdiagram.

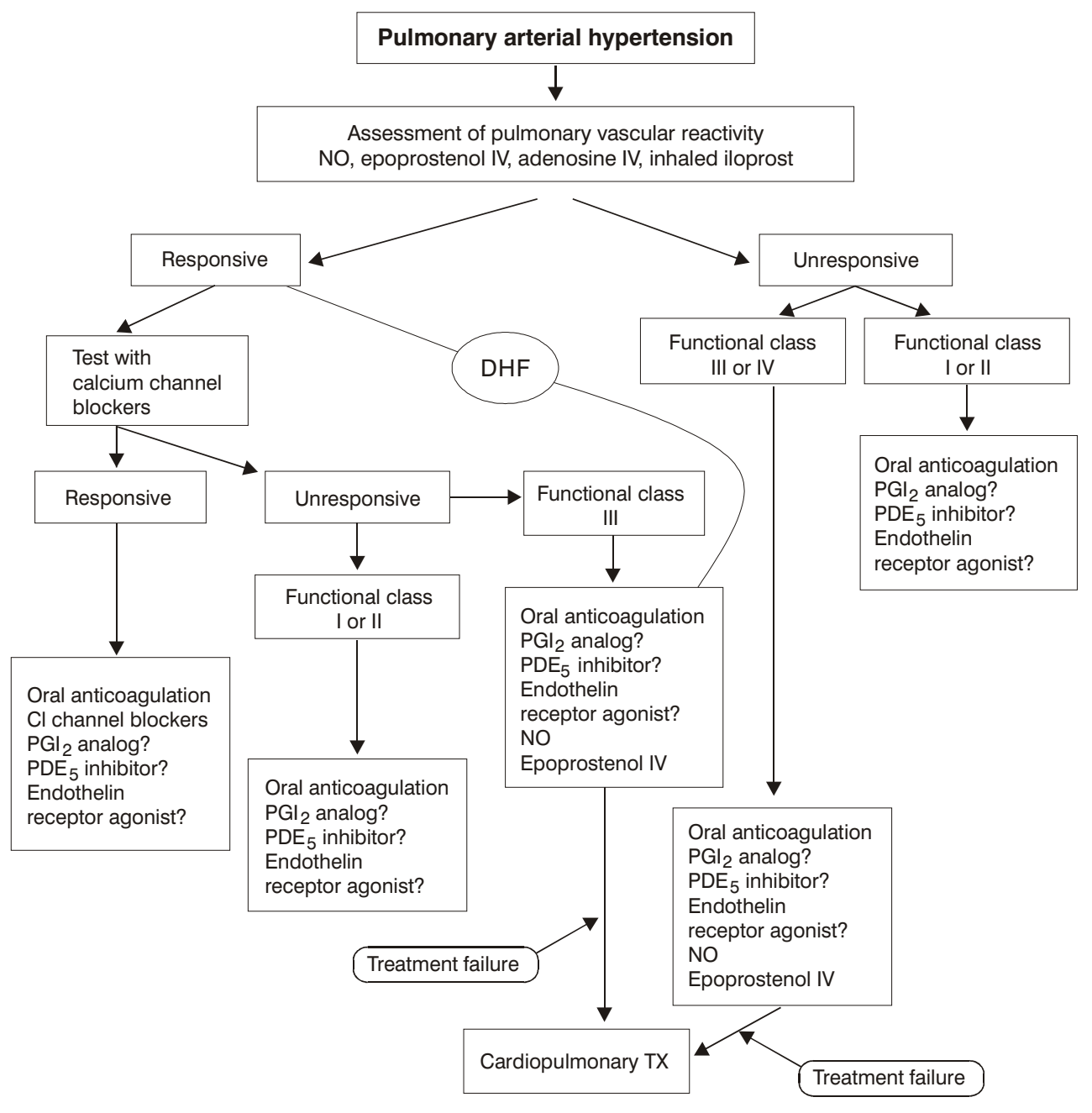

Figure 2 - Flow diagram of current treatment for pulmonary hypertension $\mathrm{DHF}=$ diastolic heart failure; $\mathrm{NO}=$ nitric oxide $\mathrm{PDE}=$ phosphodiesterase $; \mathrm{PGI}=$ phosphoglucose isomerase; $\mathrm{TX}=$ transplant. 


\section{References}

1. Leuchte $\mathrm{HH}$, Schwaiblmair M, Baumgartner RA, Neurohr CF, Kolbe T, Behr J. Hemodynamic response to sildenafil, nitric oxide, and iloprost in primary pulmonary hypertension. Chest. 2004;125:580-6.

2. Nauser TD, Stites SW. Diagnosis and treatment of pulmonary hypertension. Am Fam Physician. 2001;63:1789-98.

3. Widlitz A, Barst RJ. Pulmonary arterial hypertension in children. Eur Respir J. 2003;21:155-76.

4. Budev MM, Arroliga AC, Jennings CA. Diagnosis and evaluation of pulmonary hypertension. Cleve Clin J Med. 2003;70 Suppl 1:S9-17.

5. Barst RJ. Recent advances in the treatment of pediatric pulmonary artery hypertension. Pediatr Clin North Am. 1999;46:331-45.

6. Rosenzweig EB, Widlitz AC, Barst RJ. Pulmonary arterial hypertension in children. Pediatr Pulmonol. 2004;38:2-22.

7. Tulloh RM. Congenital heart disease in relation to pulmonary hypertension in paediatric practice. Paediatr Respir Rev. 2005;6:174-80.

8. Lang IM, Bonderman D, KneussI M, Marx M. Paediatric pulmonary vascular disease. Paediatr Resp Rev. 2004;5:238-48.

9. Rich $S$, editor. Primary pulmonary hypertension: executive summary from the World Symposium-Primary Pulmonary Hypertension 1998. http://www.who.int/ncd/dvd/pph.html Access: 02/09/2006.

10. Rubin LJ, Badesch DB, Barst RJ, Galie N, Black CM, Keogh A, et al. Bosentan therapy for pulmonary arterial hypertension. $\mathrm{N}$ Engl J Med. 2002;346:896-903.

11. Kanthapillai $P$, Lasserson TJ, Walters EH. Sildenafil for pulmonary hypertension. (Cochrane Review). In: The Cochrane Library, Issue 1. Oxford: Update Software. 2005.

12. Gozal D, O'Brien LM. Snoring and obstructive sleep apnoea in children: why should we treat? Paediatr Respir Rev. 2004;5 Suppl A):S371-6.

13. Blum RH, McGowan FX Jr. Chronic upper airway obstruction and cardiac dysfunction: anatomy pathophysiology and anesthetic implications. Pediatric Anaesth. 2004;14:75-83.

14. Berger M, Haimowitz A, Van Tosh A, Berdorff RL, Golberg E. Quantitative assessment of pulmonary hypertension in patients with tricuspid regurgitation using continuous wave Doppler ultrasound. J Am Coll Cardiol. 1985;6:359-65.

15. Chockalingam A, Gnanavelu G, Venkatesan S, Elangovan S, Jagannathan V, Subramaniam T, et al. Efficacy and optimal dose of sildenafil in primary pulmonary hypertension. Int J Cardiol. 2005; 99:91-5.

16. Homma A, Anzueto A, Peters JI, Susanto I, Sako E, Zabalgoitia $M$, et al. Pulmonary artery systolic pressures estimated by echocardiogram vs. cardiac catheterization in patients awaiting lung transplantation. J Heart Lung Transplant. 2001;20:833-9.

17. Khan MG. Pulmonary hypertension and cor pulmonale. In: Khan MG, Lynch JP III, eds. Pulmonary disease diagnosis and therapy: a practical approach. Baltimore: Williams \& Wilkins; 1997. p. 603-16.

18. Humbert M, Sitbon O, Simonneau G. Treatment of pulmonary arterial hypertension. N Engl J Med. 2004;351:1425-36.

19. Frank H, Mlczoch J, Huber K, Schuster E, Gurtner HP, Kneussl M. The effect of anticoagulant therapy in primary and anorectic drug-induced pulmonary hypertension. Chest. 1997;112:714-21.

20. Klings ES, Farber HW. Current management of primary pulmonary hypertension. Drugs. 2001;61:1945-56.

21. Rich S, Kaufmann E, Levy PS. The effect of high doses of calcium-channel blockers on survival in primary pulmonary hypertension. N Engl J Med. 1992;327:76-81.

22. Sitbon $O$, Humbert $M$, Ioos $V$. Who benefits from long term calcium-channel blocker therapy in primary pulmonary hypertension? Am J Respir Crit Care Med. 2003;167:A440.

23. Christman BW, McPherson CD, Newmann JH, King GA, Bernard GR, Groves BM, et al. An imbalance between the excretion of thromboxane and prostacyclin metabolites in pulmonary hypertension. N Eng J Med. 1992;327:70-5.

24. Tuder RM, Cool CD, Geraci MW, Wang J, Abman SH, Wright L, et al. Prostacyclin synthase expression is decreased in lungs from patients with severe pulmonary hypertension. Am J Respir Crit Care Med. 1999;159:1925-32.

25. Galie N, Humbert M, Vachiery JL, Vizza CD, KneussI M, Manes A, et al. Effects of beraprost sodium, an oral prostacyclin analogue, in patients with pulmonary arterial hypertension: a randomized, double-blind, placebo-controlled trial. J Am Coll Cardiol. 2002;39:1496-502.
26. Barst RJ, Rubin LJ, Long WA, McGoon MD, Rich S, Badesch DB, et al. A comparison of continuous intravenous epoprostenol (prostacyclin) with conventional therapy for primary pulmonary hypertension. The Primary Pulmonary Hypertension Study Group. N Engl J Med. 1996;334:296-302.

27. Badesch DB, Tapson VF, McGoon MD, Brundage BH, Rubin LJ, Wigley FM, et al. Continuous intravenous epoprostenol for pulmonary hypertension due to the scleroderma spectrum of disease. A randomized, controlled trial. Ann Intern Med. 2000;132:425-34.

28. Sitbon O, Humbert M, Nunes H, Parent F, Garcia G, Herve P, et al. Long term intravenous epoprostenol infusion in primary pulmonary hypertension: prognostic factors and survival. J Am Coll Cardiol. 2002;40:780-8.

29. McLaughlin VV, Shillington A, Rich S. Survival in primary pulmonary hypertension: the impact of epoprostenol therapy. Circulation. 2002;106:1477-82.

30. Humbert M, Sanchez O, Fartoukh M, Jagot JL, Le Gall C, Sitbon $O$, et al. Short-term and long-term epoprostenol (prostacyclin) therapy in pulmonary hypertension secondary to connective tissue diseases: results of a pilot study. Eur Respir J. 1999;13: 1351-6.

31. Kuhn KP, Byrne DW, Arbogast PG, Doyle TP, Loyd JE, Robbins IM. Outcome in 91 consecutive patients with pulmonary arterial hypertension receiving epoprostenol. Am J Respir Crit Care Med. 2003;167:580-6.

32. Simonneau G, Barst RJ, Galie N, Naeije R, Rich S, Bourge RC, et al. Continuous subcutaneous infusion of treprostinil, a prostacyclin analogue, in patients with pulmonary arterial hypertension: a double-blind, randomized, placebo controlled trial. Am J Respir Crit Care Med. 2002;165:800-4.

33. Opitz CF, Wensel R, Winkler J, Halank M, Bruch L, Kleber FX, et al. Clinical efficacy and survival with first-line inhaled iloprost therapy in patients with idiopathic pulmonary arterial hypertension. Eur Heart J. 2005;26:1895-902.

34. Nagaya N, Uematsu M, Okano Y, Satoh T, Kyotani S, Sakamani $F$, et al. Effect of orally active prostacyclin analogue on survival of outpatients with primary pulmonary hypertension. J Am Coll Cardiol. 1999;34:1188-92.

35. Hoeper MM, Schwarze M, Ehlerding S, Adler-Schuermeyer A, Spiekerkoetter E, Niedermeyer J, et al. Long-term treatment of pulmonary hypertension with aerosolized iloprost, a prostacyclin analogue. N Engl J Med. 2000;342:1866-70.

36. Barst RJ, Ivy D, Dingemanse J, Widlitz A, Schmitt K, Doran A, et al. Pharmacokinetics, safety, and efficacy of bosentan in pediatric patients with pulmonary arterial hypertension. Clin Pharmacol Ther. 2003;73:372-82.

37. Cohen $\mathrm{H}$, Chahine $\mathrm{C}$, Hui A, Mukherji R. Bosentan therapy for pulmonary arterial hypertension. Am J Health Syst Pharm. 2004;61:1107-19.

38. Channick RN, Simonneau G, Sitbon O, Robbins IM, Frost A, Tapson VF, et al. Effects of dual endothelin-receptor antagonist besentan in patients with pulmonary hypertension: a randomized placebo controlled study. Lancet. 2001;358:1119-23.

39. Galiè N, Hinderliter AL, Torbicki A, Fourme T, Simonneau G, Pulido $\mathrm{T}$, et al. Effects of the oral endothelin-receptor antagonist bosentan on echocardiographic and Doppler measures in patients with pulmonary arterial hypertension. J Am Coll Cardiol. 2003;41:1380-6

40. Rosenzweig EB, Ivy DD, Widlitz A, Doran A, Claussen LR, Yung $D$, et al. Effects of long-term bosentan in children with pulmonary arterial hypertension. J Am Coll Cardiol. 2005;46:697-704.

41. Barst RJ, Rich S, Widlitz A, Horn EM, McLaughlin V, McFarlin J. Clinical efficacy of sitaxsentan, an endothelin-A receptor antagonist, in patients with pulmonary arterial hypertension. Chest. $2002 ; 121: 1860-8$

42. Barst RJ, Langleben D, Frost A, Horn EM, Oudiz R, Shapiro S, et al. Sitaxsentan, therapy for pulmonary arterial hypertension. Am J Respir Crit Care Med. 2004;169:441-7.

43. Steudel W, Hurford WE, Zapol WM. Inhaled nitric oxide: basic biology and clinical applications. Anesthesiology. 1999;91: 1090-121.

44. Walsh-Sukys MC, Tyson JE, Wright LL, Bauer CR, Korones SB, Stevenson DK, et al. Persistent pulmonary hypertension of the newborn and role of inhaled nitric oxide: practice variation and outcomes. Pediatrics. 2000;105:14-20.

45. Goldman AP, Delius RE, Deanfield JE, Macrae DJ. Nitric oxide is superior to prostacyclin for pulmonary hypertension after cardiac operations. Ann Thorac Surg. 1995;60:300-5. 
46. Macrae DJ, Field D, Mercier JC, Moller J, Stiris T, Biban P, et al. Inhaled nitric oxide therapy in neonates and children: reaching a European consensus. Intensive Care Med. 2004;30:372-80.

47. Ng J, Finney SJ, Shulman R, Bellingan G J, Singer M, Glynne PA. Treatment of pulmonary hypertension in the general adult intensive care unit: a role for oral sildenafil? $\mathrm{Br}$ J Anaesth. 2005; 114:1-4.

48. Atz AM, Wessel DL. Sildenafil ameliorates effects of inhaled nitric oxide withdrawal. Anesthesiology. 1999;91:307-10.

49. Prasad S, Wilkinson J, Gatzoulis MA. Sildenafil in primary pulmonary hypertension. N Engl J Med. 2000;343:1342.

50. Bigatello LM, Hess D, Dennehy KC, Medoff BD, Hurford WE. Sildenafil can increase the response to inhaled nitric oxide. Anesthesiology. 2000;92:1827-9.

51. Abrams D, Schulze-Neick I, Magee AG. Sildenafil as a selective pulmonary vasodilator in childhood primary pulmonary hypertension. Heart. 2000;84:E4.

52. Weimann J, Ullrich R, Hromi J, Fujino Y, Clark MW, Bloch KD, et al. Sildenafil is a pulmonary vasodilator in awake lambs with acute pulmonary hypertension. Anesthesiology. 2000;92: 1702-12.

53. Zhao L, Mason NA, Morrel NW, Kojonazarov B, Sadykov A, Maripov A, et al. Sildenafil inhibits hypoxia-induced pulmonary hypertension. Circulation. 2001;104:424-8.

54. Ichinose F, Erana-Garcia J, Hromi J, Raveh Y, Jones R, Krim L, et al. Nebulized sildenafil is a selective pulmonary vasodilator in lambs with acute pulmonary hypertension. Crit Care Med. $2001 ; 29: 1000-5$

55. Shekerdemian LS, Ravn HB, Penny DJ. Intravenous sildenafil lowers pulmonary vascular resistance in a model of neonatal pulmonary hypertension. Am J Respir Crit Care Med. 2002;165: 1098-102.

56. Kleinsasser A, Loeckinger A, Hoermann C, Puehringer F, Mutz N, Bartsch G, et al. Sildenafil modulates hemodynamics and pulmonary gas exchange. Am J Respir Crit Care Med. 2001;163:339-43.

57. Cheitlin M, Hutter AM Jr., Brindis RG, Ganz P, Kaul S, Russell RO Jr., et al. Use of sildenafil (Viagra) in patients with cardiovascular disease. Technology and Practice Executive Committee. Circulation. 1999;99:168-77.

58. Keller RL, Hamrick SE, Kitterman JA, Fineman JR, Hawgood S. Treatment of rebound and chronic pulmonary hypertension with oral sildenafil in an infant with congenital diaphragmatic hernia. Pediatr Crit Care Med. 2004;5:184-7.

59. Wilkens H, Guth A, Konig J, Forestier N, Cremers B, Hennen B, et al. Effect of inhaled iloprost plus oral sildenafil in patients with primary pulmonary hypertension. Circulation. 2001;104: 1218-22.

60. Jimenez López-Guarch $C$, Escribano Subias $P$, Tello de Meneses R, Delgado Jimenez JF, Sadia Peres D, Velazquez Martin MT, et al. Efficacy of oral sildenafil as rescue therapy in patients with severe pulmonary arterial hypertension chronically treated with prostacyclin. Long-term results. Rev Esp Cardiol. 2004;57: 946-51.

61. Kataoka M, Satoh T, Manabe T, Anzai T, Yoshikawa T, Mitamura $\mathrm{H}$, et al. Oral sildenafil improves primary hypertension refractory to epoprostenol. Circ J. 2005;69:461-5.

62. Ikeda D, Tsujino I, Ohira H, Itoh N, Kamigaki M, Ishimaru S, et al. Addition of oral sildenafil to beraprost is a safe and effective therapeutic option for patients with pulmonary hypertension. J Cardiovasc Pharmacol. 2005;45:286-9.
63. Trachte AL, Lobato EB, Urdaneta F, Hess PJ, Klodell CT, Martin TD, et al. Oral sildenafil reduces pulmonary hypertension after cardiac surgery. Ann Thorac Surg. 2005;79:194-7.

64. Schulze-Neick I, Hartenstein P, Li J, Stiller B, Nagdyman N, Hubler $\mathrm{M}$, et al. Intravenous sildenafil is a potent pulmonary vasodilator in children with congenital heart disease. Circulation. 2003;108 Suppl 1:II167-73.

65. Bentlin MR, Saito A, De Luca AK, Bossolan G, Bonatto RC, Martins AS, et al. Sildenafil no tratamento da hipertensão pulmonar após cirurgia cardíaca. J Pediatr (Rio J). 2005;81:175-8.

66. Cantrell FL. Sildenafil citrate ingestion in a pediatric patient. Pediatr Emerg Care. 2004;20:314-5.

67. Clouzeau J, Paihle L, Rakotonirina G. Accidental ingestion of sildenafil (Viagra) by a child. Arch Pediatr. 1999;6:904

68. Marsh CS, Marden B, Newson R. Severe retinopathy of prematurity (ROP) in a premature baby treated with sildenafil acetate (Viagra) for pulmonary hypertension. Br J Ophthalmol. 2004; 88:306-7.

69. Pierce $C M$, Petros AJ, Fielder AR. No evidence for severe retinopathy of prematurity following sildenafil. $\mathrm{Br} \mathrm{J}$ Ophthalmol. 2005;89:250.

70. Ricachinevsky CP, Amantea SL. Efeitos imediatos do sildenafil na hipertensão arterial pulmonar de pacientes pediátricos [dissertação]. Porto Alegre: Fundação Federal Faculdade Ciências Médicas de Porto Alegre; 2005.

71. Stiebellehner L, Petkov V, Vonbank K, Funk G, Schenk P, Ziesche $R$, et al. Long-term treatment with oral sildenafil in addition to continuous IV epoprostenol in patients with pulmonary hypertension. Chest. 2003;123:1293-5.

72. Hoeper MM, Taha N, Bekjarova A, Gatzke R, Spiekerkoetter E. Bosentan treatment in patients with primary pulmonary hypertension receiving nonparenteral prostanoids. Eur Respir J. 2003;22:330-4.

73. Kerstein D, Levy PS, Hsu DT, Hordof AJ, Gersony WM, Baerst RJ. Blade balloon atrial septostomy in patients with severe primary pulmonary hypertension. Circulation. 1995;91:2028-35.

74. Sandoval J, Gaspar J, Pulido T, Bautista E, Martinez-Guerra ML, Zeballos $M$, et al. Graded balloon dilation atrial septostomy in severe primary hypertension. A therapeutic alternative for patients nonresponsive to vasodilator treatment. J Am Coll Cardiol. 1998;32:297-304.

75. Pasque MK, Trulock EP, Cooper JD, Triantafillou AN, Huddleston $C B$, Rosenbloom $M$, et al. Single lung transplantation for pulmonary hypertension. Single institution experience in 34 patients. Circulation. 1995;92:2252-8.

76. Spray $T L$, Bridges ND. Lung transplantation for pediatric pulmonary hypertension. Prog Pediatr Cardiol. 2001;12:319-25.

77. Camargo JJ, Grupo de Transplante Pulmonar da Santa Casa de Porto Alegre, RS, Brasil. Transplante pulmonar na infância. J Pediatr (Rio J). 2002;78 Suppl. 2:S113-22.

Correspondence:

Sérgio L. Amantéa

Rua Passo da Pátria, 508/901 - Bela Vista

CEP: 90460-060 - Porto Alegre, RS - Brazil

Fone/Fax: +55 (51) 3334.0146

E-mail: samantea@santacasa.tche.br 